\title{
Editorial
}

\section{In honor of Professor Giovanni Fadda: a fighter against tuberculosis}

\author{
Stefania Zanetti ${ }^{1}$, Leonardo A. Sechi ${ }^{1}$, Paola Molicotti ${ }^{1}$, Giovanni Delogu ${ }^{2}$, Maurizio Sanguinetti ${ }^{2}$ \\ Salvatore Rubino ${ }^{1,3}$ \\ ${ }^{1}$ Department of Biomedical Sciences, University of Sassari, Sassari, Italy \\ ${ }^{2}$ Institute of Microbiology, Catholic University of the Sacred Hearth, Rome, Italy \\ ${ }^{3}$ Editor-in-Chief, Journal of Infection in Developing Countries
}

Key words: tuberculosis; mycobacteria

J Infect Dev Ctries 2013; 7(3):159-160.

(Received and Accepted 05 March 2013)

Copyright (C) 2013 Zanetti et al. This is an open-access article distributed under the Creative Commons Attribution License, which permits unrestricted use, distribution, and reproduction in any medium, provided the original work is properly cited.

This issue of the Journal of Infection in Developing Countries is a celebration of 50 years of dedicated infectious disease research by Professor Giovanni Fadda. As an internationally renowned microbiologist, Professor Fadda was dedicated to the fight against tuberculosis. Throughout his career, he worked in developing countries establishing laboratories for the identification of mycobacteria. He was one of the first scientists to help JIDC in its initial steps, and he is a key member of the mentoring committee of the journal.

On 31 October 2011, Professor Giovanni Fadda, full professor of microbiology at the Catholic University of the Sacred Heart in Rome, retired after 50 years of studies and research in the field of general and clinical microbiology. Professor Fadda was born in Tempio Pausania, Sardinia, Italy, in 1938. He achieved the degree of medical doctor in Parma with distinction in 1963 under the guidance of Professor Antonio Sanna, a pioneer of microbiology in Italy. He then obtained specialties in microbiology (1965) and in Pathology (1967) and since 1971 he has been appointed as professor of microbiology in the Universities of Parma and Sassari. From 1978 to1985 he served as Chief of the Clinical Laboratory of the Regional General Hospital of Sassari. Professor Fadda was subsequently promoted full professor of microbiology at the University of Sassari (1986-1995). During this period, he was elected Dean of the Faculty of Mathematics, Physics and Natural Sciences (19891995). At the end of 1995, he was appointed to the prestigious Catholic University of Rome as Director of the Microbiology Department and Director of the Microbiology Specialty School until 2011, at which time he became Director of the Department of Diagnosis of Morphologic, Microbiological and Blood Diseases of the Policlinico A. Gemelli, Rome.

Professor Fadda is past president of the Italian Society of Microbiology and served as President of the society for several years. As a member of numerous scientific societies (American Society for Microbiology, New York Academy of Science, and European Society of Mycobacteriology), he was very active in organizing and hosting different national and international meetings, such as the National Meeting of the Italian Society of Microbiology (1995, 2003, 2008) and the European Society for Mycobacteriology $(1995,2004)$.

With scientific interests spanning different areas of microbiology including virology, bacteriology, diagnostic microbiology and molecular biology, Professor Fadda has published more than 350 international papers in prestigious peer-reviewed journals including Nature, Molecular Microbiology, the Journal of Infectious Diseases, Clinical Infectious Diseases, Thorax, and AIDS among others. The strong impact of his publications within the scientific community is testified by the high reputation he holds among scholars and by the now very popular bibliometric scores that put him among the top scientists in the field [1].

As a microbiologist, he has been a strong advocate of scientific research. He started working with viruses, in particular arboviruses [2] and Sarcoma virus, and remained active in this line of research throughout his entire career, with more than 70 international publications in this field. 
In particular, Professor Fadda made significant contributions to the field of tuberculosis, adding to the canon of knowledge on the biology of Mycobacterium tuberculosis and its pathogenic mechanisms. Although tuberculosis was once considered a disease of the past, it is still a major problem todays. It is the third cause of mortality in the world, and a major health issue in developing countries, where Professor Fadda made a significant impact on the realization of modern microbiological laboratories in resource-poor settings [3]. He developed an original holistic approach to the tuberculosis problem, which bridged basic and applied research and led to the generation of innovative diagnostic, prophylactic and therapeutic systems. Professor Fadda pioneered work and published influential papers on the use of radiometric methods to diagnose extrapulmonary $M$. tuberculosis infections [4]; molecular epidemiology of TB [5]; innovative non-invasive $M$. tuberculosis detection systems [6]; the regulation of $M$. tuberculosis virulence proteins [7]; the role of PE-PGRS proteins [8]; and the development of innovative vaccines against tuberculosis [9].

To celebrate the fifth year of the foundation of the JIDC, Professor Fadda wrote an important editorial titled "Tuberculosis: novel approaches to an old diseases" [10] as well as a very helpful review on the development of new vaccines against tuberculosis [11].

In addition to his many other merits, Professor Giovanni Fadda had the ability through his scientific and academic career to combine a high level of scientific activity with its application to the field. His many scientific achievements throughout a brilliant career have been recognized through the many appointments with which he has been honored at both national and international levels, such as those for the World Health Organization in countries such as Iran, Pakistan, and Palestine.

Colleagues from all over Italy and other countries attended his final Lectio Magistralis in Rome, which summarized the most relevant and important topics to address in the future if we are to conquer the ancient scourge of TB.

Many of us under his guidance and leadership learned how to be a scientist and what a scientist is; we now stand as his friends, collaborators, and colleagues. We have had the fortune to work for many years by his side and we will treasure his teaching as well as its witty advice. Like a hero in a great opera, Professor Fadda will continue to inspire us for years to come, and we will always remember one of his many adages that demonstrates his attachment to his native land: "Research is like a pig: do not throw anything away."

JIDC is proud to dedicate this issue to a master of life and science, a mentor for young scientists, medical doctors and laboratory specialists, especially those in developing countries. We thank all the authors, editors, and others who collaborated with JIDC on this initiative.

\section{References}

1. http://www.scopus.com/home.url. Last accessed 2 March 2013.

2. Mussgay M, Fadda G, Peralta M (1967) Simple method for preparation of haemagglutinating arbo-A virus antigens from brains of suckling mice. Nature 213: 304-305.

3. Fadda G, De Virgilio G, Mantellini P, Piva P, Sertoli M (1988) The organization of laboratory services for a "Tuberculosis Control Programme". J Pak Med Assoc 38: 187-193.

4. Fadda G and Roe SL (1984) Recovery and susceptibility testing of Mycobacterium tuberculosis from extrapulmonary specimens by the BACTEC radiometric method. J Clin Microbiol 19: 720-721.

5. Sechi LA, Zanetti S, Dupré I, Aceti A, Sanguinetti M, Fadda G (1998) Genotypic changes in DNA fingerprinting patterns of Mycobacterium tuberculosis strains from HIV-positive persons in Sardinia. AIDS 12: 2084-2086

6. Aceti A, Zanetti S, Mura MS, Sechi LA, Turrini F, Saba F, Babudieri S, Mannu F, Fadda G (1999) Identification of HIV patients with active pulmonary tuberculosis using urine based polymerase chain reaction assay. Thorax 54: 145-146.

7. Delogu G, Sanguinetti M, Posteraro B, Rocca S, Zanetti S, Fadda G (2006) The hbhA gene of Mycobacterium tuberculosis is specifically upregulated in the lungs but not in the spleens of aerogenically infected mice. Infect Immun 74: 3006-3011.

8. Delogu G, Sanguinetti M, Pusceddu C, Bua A, Brennan MJ, Zanetti S, Fadda G (2006) PE_PGRS proteins are differentially expressed by Mycobacterium tuberculosis in host tissues. Microbes Infect. 8: 2061-2067.

9. Sali M, Clarizio S, Pusceddu C, Zumbo A, Pecorini G, Rocca S, Zanetti S, Delogu G, Fadda G. (2008) Evaluation of the anti-tuberculosis activity generated by different multigene DNA vaccine constructs. Microbes Infect 10: 605-612.

10. Fadda G (2012) Tuberculosis: novel approaches to an old disease. J Infect Dev Ctries 6: 4-5.

11. Delogu $G$ and Fadda G (2009) The quest for a new vaccine against tuberculosis. J Infect Dev Ctries 3: 5-15.

\section{Corresponding author}

Prof. Stefania Zanetti

Dipartimento di Scienze Biomediche

Viale San Pietro 43 B

07100 Sassari, Italy

Telephone/Fax: 079 228463/079212345

Email: zanettis@uniss.it

Conflict of interests: No conflict of interests is declared. 